\title{
Antioxidant Activity and Ethno pharmacological Survey of Achillea biebersteinii Afan. in the Treatment of Dysmenorrhoea in Traditional Medicine of Golestan Province, Iran
}

\author{
Masoumeh Mazandarani ${ }^{1 *}$, Nargess Osia ${ }^{2}$, Mohammad Ghafourian ${ }^{3}$
}

\begin{abstract}
Objectives: Achillea biebersteinii Afan. has been used as antispasmodic and sedative agent to treat dysmenorrhoea in traditional medicine of Golestan province. The present study was conducted to evaluate the antioxidant activity. It is also an ethno pharmacological survey of Achillea biebersteinii Afan., as antispasmodic and sedative agent in treating dysmenorrhoea in traditional medicine of Golestan province.

Materials and Methods: Ethno pharmacological data was obtained as field observation among well-known indigenous rural healers (68-82 ages) in southwest of Golestan province in August 2011. The data gathered evaluated the potential of Achillea biebersteinii in preventing or treating dysmenorrhoea. Flowers of the plant were collected in July 2012 at an altitude of 2600 meters, ethanol extract was obtained by Maceration and antioxidant capacity was obtained by 1,1-diphenyl-2-picryl hydrazyl radical scavenging (DPPH). Results: Results showed that in traditional medicine of Golestan province, the flowers of Achillea biebersteinii has been used in combination with Peganum harmala, Mentha aquatica, Cuminum cyminum, Foeniculum vulgare and Nigella sativa as antispasmodic, anti-inflammation and sedative agent to treat stomach ache, dysmenorrhoea, facial flushing, cramps and menopause. Also the ethanol extract of the plant is a very good free radical scavenging with the highest antioxidant activity (IC50 $=1.27 \pm 0.1 \mu \mathrm{g} / \mathrm{ml}$ in dry weight).

Conclusion: These finding not only confirm the use of the plant in the traditional medicine of Golestan province, but also can serve as a basis for phytochemical and pharmaceutical researches to identify and produce effective herbal drugs in prevention or treatment of common dysmenorrhoea.

Keywords: Achillea biebersteinii Afan., Antioxidant, Dysmenorrhoea, Ethno pharmacology
\end{abstract}

\section{Introduction}

In the past two decades, increasing consumption of synthetic drugs and its associated side effects has led World Health Organization (WHO) to study the antioxidant activity of this plant. It also conducted an ethno botanical survey of endemic medicinal plants studying its uses by the rural populations in order to prevent and treat many current diseases (1).

Achillea species such as Achillea millefolium and Achillea biebersteinii Afan. are antispasmodic, anti- inflammatory, antiulcer and antioxidant agents mainly used for gastrointestinal disorders, estrogen-related effects, menstrual irregularities, wound care and skin inflammation $(2,3)$. Achillea biebersteinii Afan. locally named as "Yellow marabou" in Asteraceae family, is a wide spread medicinal plant, found mainly in Europe, Asia and the USA. Its flowers appear from June to September and are widely used as antiulcer, antispasmodic, anti-inflammatory and anti hemorrhagic agent treating numerous illnesses, and especially used as sedative in treating dysmenorrhoea (4). Rural communities in the mountainous southwest region of Golestan province (namely Charbagh and Deraznoo areas) in north of Iran have a long original tradition of using plants as an antispasmodic, antiseptic , sedative and anti-inflammatory agent to treat gastrointestinal disorders, dyspeptic complaints, stomach ache, dysmenorrhoea and dysmenorrhoea (5). Thus this study was carried out and extensive data on the antioxidant activity of Achillea biebersteinii Afan. was collected from the proficient local practitioners of ethnic traditional medicine in Golestan province.

\section{Materials and Methods \\ Ecological requirements and ethno pharmacology}

In the present field observation, we analyzed the ecological requirements and traditional pharmaceutical knowl- 
edge on Achillea biebersteinii Afan. in two small mountainous villages isolated in steppe areas within latitudes of $55^{\circ} 57^{\prime} 55^{\prime \prime}$ to $52^{\circ} 57^{\prime} 55^{\prime \prime}$ and longitudes of $25^{\circ} 46^{\prime} 37^{\prime \prime}$ to $15^{\circ} 42^{\prime} 37^{\prime \prime}$, covering an area of 2800 hectares in southwest of Golestan province (Charbagh and Deraznoo), having several steppe and semi steppe ranges reaching 1800 to 2600 meters respectively, with semi-dry and cold climate. For traditional interviews, all data on plant uses, its local name, plant part and the preparation methods of traditional drugs were obtained through interviews with the practitioners and housewives (56-68 years), analyzed and compared with other findings in similar reports.

\section{Plant material}

The aerial parts of blooming plant were collected in late July 2012 from the Charbagh Mountain in southeast of Golestan province (north of Iran). The plant was identified in RCMP (Research Center of Medicine Plant) with voucher specimen (No. HRCMP:451), preserved and deposited in the herbarium of Islamic Azad University of Gorgan branch, Gorgan, Iran.

\section{Extraction and isolation}

Sixty grams of air-dried plant flowers were exhaustively extracted with $470 \mathrm{ml}$ methanol by maceration extraction and concentrated by using a rotary evaporator.

\section{Antioxidant activity tests}

2,2-Diphenyl-1-picrylhydrazyl radical scavenging capacity assay

The ability of the extract for free radical scavenging was assessed by Arabshahi et al. method (6). The aliquots of plant extract $(20,40,60,80,100 \mu \mathrm{l})$ were mixed with a methanol solution of DPPH- $(1 \mathrm{~mm}, 600 \mu \mathrm{l})$ and brought to $6 \mathrm{ml}$ with solvent. After incubating in dark and at room temperature the absorbance was measured at $517 \mathrm{~nm}$. A DPPH- blank sample (containing $5.4 \mathrm{ml}$ of methanol and $600 \mu \mathrm{l}$ of DPPH-solution) was prepared. The percent decrease in absorbance was recorded for each concentration and percentage inhibition was calculated according to the following formula: $\%$ inhibition $=\left[\left(\mathrm{ADPPH}_{-} \mathrm{A}\right.\right.$ plant extract)/ADPPH] $\times 100$. ADPPH is the absorbance value of the DPPH- blank sample and extract is the absorbance value of the test solution. The plots of the 'percentage inhibitions amounts of dried plants (mg) in the extract' were used to find the concentration at which $50 \%$ radical scavenging occurred (IC50).

\section{Results}

Ecological data showed that Achillea biebersteinii Afan. with local name of "Yellow Marambou" is a perennial wild herb $(10-40 \mathrm{~cm})$, growing in cool dry climate and sandy clay loam soils (1200-2600 m), requiring an average rainfall of 305.9-414.8 mm, Ec=0.73-2.5. The yellow inflorescences of the plant appear from June to September. Laboratory test showed that the flowers extract had very good antioxidant activity and high potency in scavenging of free radicals (IC50 $=1.27 \pm 0.1 \mu \mathrm{g} / \mathrm{ml}$ in dry weight). Ethno pharmacological data showed that the flowers of Achillea biebersteinii Afan. have been considered as safe medicinal plants as a tonic, antispasmodic, sedative, anti-inflammatory and anticholinergic agent in treating dysmenorrhoea. The dosages for various conditions are as below:

Stomach ache and pain relief: The tea of Achillea biebersteinii Afan., 5-7 seeds of Peganum harmala and aerial parts of Mentha aquatica.

Dysmenorrhoea: The tea of Achillea biebersteinii Afan., Matricaria species, Cuminum cyminum, Foeniculum vulgare, Stachys lavandulifolia, Ziziphus vulgaris and the seeds of Nigella sativa.

Amenorrhea: Every night 1 cup of Achillea biebersteinii Afan. and Foeniculum vulgare distilled with 1 tea spoon of honey.

Internal bleeding: The decoction of Achillea biebersteinii Afan., Myrtus communis, Plantago psyllium, Malva neglecta, Cydonia seeds and honey, peptic ulcer (infusion of Achillea biebersteinii Afan., Teucrium polium, flowers and the root of Malva neglecta in combination with Amygdalus oil and Ferula assafoetida), dryness in the mouth and facial flushing (Urtica dioica, Achillea biebersteinii Afan. or Achillea millefolium and Foeniculum vulgare) and in palpitation Achillea micranta, Salix aegyptiaca, Citrus aurantium and Crataegus oxyantha have been used.

Leishmaniasis: The poultice of tincture of Perovskia abrotanoides, Artemisia annua and Achillea biebersteinii Afan.

\section{Discussion}

Dysmenorrhoea (painful periods) is a medical condition of pain during menstruation that interferes with daily activities. It has long been treated by medicinal plant species in traditional medicine of countries (7).

Achillea biebersteinii Afan. is one of the most common herbs used as a tonic, sedative, antispasmodic and anticholinergic agent to treat various cold, wounds, hay fever and dysmenorrhoea. Additionally, it has also been used to help to regulate the menstrual cycle, promote menstruation while reducing heavy bleeding, and relieving dysmenorrhoea. All these medicinal effects have also been reported by other researchers worldwide $(8,9)$.

In similar studies it was reported that the binopacryle (63.82\% to $83.63 \%), 1-8$ cineol ( $14.97 \%$ to $3.76 \%)$, a-selinene $(4.81 \%$ to $4.49 \%)$, phenols $(18.44 \pm 0.085$ mgGAE g-1) and flavonoid contents (80.30 \pm 5.793 mgQUE g-1) were the main chemical composition of Achillea biebersteinii Afan. which are responsible for the antioxidant and antispasmodic activity of Achillea species (10).

To confirm our ethno pharmacological results, other researchers showed that alkaloids (harmine, $\beta$-carboline, peganine, harmalol, harmaline and vasicine) present in the seeds of Peganum harmala L. (11) and camphor, myrcene, cineole, caryophyllene, linalool and sesquiterpene lactones were the most prevalent secondary metabolites in the flower extracts of Achillea species, being effective as antispasmodic and sedative agent treating dysmenorrhoea and stomach ache $(5,8,9)$.

Chamazulene, eucalyptol, camphor, alpha-terpineol, be- 
ta-pinene and borneol which are present in many volatile oils of Achillea species, are well-known antioxidant, anti-inflammatory, anti allergic agents with antispasmodic action on rat duodenum against a variety of antitumor cell lines in mouse (8). Flavonoids (apigenin, rutin, luteolin and campherol), and monoterpenes (alpha-pinene, 1,8-cineole and camphor) are believed to be the source of the yarrow's antispasmodic benefits, while the alkaloid, achilleine, is believed to help control both internal and external bleeding. Meanwhile their amounts vary within different species based on ecological factors and climatic condition in different geographical regions $(10,12,13)$.

In Traditional Chinese Medicine (TCM), the flowers of Achillea species has been used for a variety of conditions such as bleeding, wounds, haemorrhoids, varicose veins, dysmenorrhoea and tuberculosis condition (3). In the entire American continent, the most important uses were for skin problems and injuries, bleeding conditions, respiratory illnesses, digestive problems, toothaches and eye problems (14). Karamenderes and Apaydin demonstrated that ethanol extract Achillea micrantha exhibits an inhibitory effect on the dose-response curves induced by acetylcholine and $\mathrm{CaCl}_{2}$ on rat duodenum (13).

Some researchers have also reported that Teucrium polium L., Peganum harmala L. and Achillea millefolium L. , contain harmine, harmaline, vasicinone, deoxyvasicinone, achillin, limonene, borneol, $\alpha$-cadinol, caryophyllene oxide and terpinen-4-ol alkaloids $(15,16)$. According to other reports the terpenoids (eucalyptol, camphor, a-terpineol, $\beta$-pinene, and borneol ) are the principal components of Achillea millefolium L. oil with the strongly radical scavenging $(\mathrm{IC} 50=1.56 \mu \mathrm{g} / \mathrm{ml})$, antispasmodic, anti cholinergic and antibacterial activity against Streptococcus pneumoniae, Clostridium perfringens, Candida albicans, Mycobacterium smegmatis, Acinetobacter lwoffii and Candida krusei (17-19). Thus these results confirmed that the oil and extract of Achillea species possess antioxidant, antispasmodic and antimicrobial properties in vitro and thus in the treatment of dysmenorrhoea.

\section{Conclusion}

These data are the first reports on antioxidant activity and ethno pharmacological information of Achillea biebersteinii Afan. It is used as antispasmodic and anti-inflammatory agent in the traditional medicine of Golestan province to treat wounds, skin infections, abdominal pain, leishmaniosis infection and dysmenorrhoea. It is notable that it can serve as a basis for phytochemical and pharmaceutical studies to identify and produce effective herbal drugs in prevention and treatment of common regional diseases.

\section{Ethical issues}

The local ethics committee approved the study.

\section{Conflict of interests}

Authors declare that there is no any conflict of interest.

\section{Acknowledgments}

The article was part of research project under the code of 1354847. The research team thanks all people helping the project to be carried out, especially the Research Director of Research Center of Medicinal Plant (RCMP in Islamic Azad University of Gorgan branch) and Golestan University of Medical Science.

\section{References}

1. Idolo M, Motti R, Mazzoleni S. Ethnobotanical and phytomedicinal knowledge in a long-history protected area, the Abruzzo, Lazio and Molise National Park (Italian Apennines). J Ethnopharmacol 2010 3;127(2):379-95. doi: 10.1016/j.jep.2009.10.027.

2. de Souza P, Gasparotto A Jr, Crestani S, Stefanello MÉ, Marques MC, da Silva-Santos JE, et al. Hypotensive mechanism of the extracts and artemetin isolated from Achillea millefolium L. (Asteraceae) in rats. Phytomedicine 2011;18(10):819-25. doi: 10.1016/j. phymed.2011.02.005.

3. Radulović NS, Dekić MS, Ranđelović PJ, Stojanović NM, Zarubica AR, Stojanović-Radić ZZ. Toxic essential oils: anxiolytic, antinociceptive and antimicrobial properties of the yarrow Achillea umbellata Sibth. et Sm.(Asteraceae) volatiles. Food Chem Toxicol 2012;50(6):2016-26. doi: 10.1016/j. fct.2012.03.047

4. Khan AU, Gilani AH. Blood pressure lowering, cardiovascular inhibitory and bronchodilatory actions of Achilleamillefolium. Phytother Res 2011;25(4):577-83. doi: 10.1002/ptr.3303.

5. Mazandarani, M. Ethnobotany and folk pharmaceutical knowledge of the major trees or shrubs in North of Iran. J Plant Sci Res 2006;1(2):1-7.

6. Arabshahi-Delouee S, Urooj A. Antioxidant properties of various solvent extracts of mulberry (Morus indical L.) leaves. Food Chem 2006;102(4):1233-1240.

7. JanssenEB, Rijkers AC,HoppenbrouwersK, Meuleman C, D'Hooghe TM. Prevalence of endometriosis diagnosed by laparoscopy in adolescents with dysmenorrhea or chronic pelvic pain: A systematic review. Human Reprod Update 2013;19(5):570-82. doi: 10.1093/humupd/dmt016.

8. Ugulu I, Baslar S, Yorek N, Dogan Y. The investigation and quantitative ethnobotanical evaluation of medicinal plants used around Izmir province, Turkey. J Medicinal Plants Res 2009;3(5):345-367.

9. Jalali Nadoushan MR, Ghosian Moghaddam $\mathrm{MH}$, Chegini V, Jafari H, Zaeri F. Evaluation of anti spermatogenic effects of Yarrow in mice. ZJRMS 2008;10(3):219-225.

10. Mazandarani $M$, Osia $\mathrm{N}$, Mosavi AK, Bayat $\mathrm{H}$. Ecological requirements, antioxidant activity and new chemotype essential oil from Achillea millefolium L. and Achilleamicrantha Wild. in north of Iran (Golestan Province). J Medicinal Plants By-products 2013;2(1):33-42.

11. Fathiazad F, Azarmi Y, Khodaie L. Pharmacological 
effects of Peganum harmala seeds extract on isolated rat uterus. Iranian J Pharm Sci 2006;2(2):81-86.

12. Bimbiraite $K$, Ragažinskienė $O$, Maruška A, Kornyšova O. Comparison of the chemical composition of four yarrow (Achillea millefolium L.) morphotypes. Biologija 2008;54(3):208-212.

13. Karamenderes C, Apaydin S. Antispasmodic effect of Achillea nobilis L. subsp. sipylea (O. Schwarz) Bassler on the rat isolated duodenum. J Ethnopharmacol 2003;84(2-3):175-9.

14. Applequist WL, Moerman DE. Yarrow (Achillea millefolium L.): A review of ethno botany, bioactivity, and biomedical research. Economic Botany 2011;65(2):209-25.

15. Ahmadian-Attari MM, Esfahani HRM, Amin GR, Fazeli MR, Jamalifar H, Kamalinia G, et al. The ethnopharmacological study on antibacterial activity of some selected plants used in Iranian traditional medicine. J Medicinal Plant 2009;8(31):50-57.
16. Jaimand K, Rezaei MB, Mozaffarian V. Chemical constituents of the leaf and flower oils from Achillea millefolium ssp. Elbursensis Hub.-Mor. from Iran rich in Chamazulene. J Essent Oil Res 2006;18(3):293-295. doi: 10.1080/10412905.2006.9699093

17. Moghaddaszadeh A, Faridi O, Shams-Ardakani M, Ghasemi Y. Medicinal smokes. J Ethnopharmacol 2006;108:161-184.

18. Candan F, Unlu M, Tepe B, Daferera D, Polissiou M, Sökmen A, et al. Antioxidant and antimicrobial activity of the essential oil and methanol extracts of Achillea millefolium subsp. millefolium Afan. (Asteraceae). J Ethnopharmacol 2003;87(2-3):215-20.

19. Moradi MT, Rafieian-Koupaei M, Imani-Rastabi R, Nasiri J, Shahrani M, Rabiei Z, et al. Antispasmodic effects of yarrow (Achilleamillefolium L.) extract in the isolated ileum of rat. Afr J Tradit Complement Altern Med 2013;10(6):499-503.

Copyright $\odot 2015$ The Author(s); This is an open-access article distributed under the terms of the Creative Commons Attribution License (http://creativecommons.org/licenses/by/4.0), which permits unrestricted use, distribution, and reproduction in any medium, provided the original work is properly cited. 